\title{
Cyclosporine Inhibition of Calcineurin Activity in Human Leukocytes In Vivo is Rapidly Reversible
}

\author{
Thomas D. Batiuk, Feldzgeritta Pazderka, Janet Enns, Liza DeCastro, and Philip F. Halloran \\ Department of Medicine, Division of Nephrology \& Immunology University of Alberta, Edmonton, Alberta, T6G 2R8, Canada
}

\begin{abstract}
Despite increasing information about the mechanism of action of cyclosporine A (CsA), little is known about the way lymphocytes recover from CsA. Recovery is central to understanding the pharmacodynamics of CsA in vivo. We studied the recovery of calcineurin phosphatase $(\mathrm{CN})$ activity in CsA-treated cells. Single dose kinetics in renal transplant patients showed that inhibition of $\mathrm{CN}$ activity in PBL increased and fell concomitant with CsA blood levels. In vitro, control PBL treated with CsA $100 \mu \mathrm{g} / \mathrm{l}$, washed, and resuspended in CsA-free medium showed little recovery ( 0 $20 \%$ ) after $\mathbf{2 4} \mathrm{h}$. Erythrocytes or anti-CsA Ab added to the recovery medium increased recovery to $50 \%$ within $4 \mathrm{~h}$. Similar recovery was seen in the ability of cells to produce IFN- $\gamma$ after OKT3 stimulation. Recovery of CN activity was associated with the efflux of $\left[{ }^{3} \mathrm{H}\right] \mathrm{CsA}$, was not blocked by cycloheximide and was temperature sensitive. A cell line with high expression of surface $P$ glycoprotein (PGP), showed rapid recovery. However, PGP blockade did not prevent recovery in $\mathrm{PBL}$, indicating a different PGP-independent mechanism. In PBL, recovery from CsA is slow and limited in vitro, but rapid in vivo, where CsA equilibrates among a complex set of extralymphocytic binding sites. (J. Clin. Invest. 1995. 96:1254-1260.) Kew words: Pglycoprotein - transplantation - immunosuppression • cyclophilin $\cdot$ rejection
\end{abstract}

\section{Introduction}

Cyclosporine $\mathrm{A}(\mathrm{CsA})^{1}$ is the cornerstone of maintenance immunosuppression in solid organ transplantation and is finding application in the treatment of autoimmune disease. In vitro, CsA binds to cyclophilin (CyP), a ubiquitous intracellular protein, and undergoes a conformational change (1-3). The CsACyP complex binds to calcineurin $(\mathrm{CN})$ and inhibits its serinethreonine phosphatase activity (4-6). We have recently reported that CsA-treated renal transplant patients have only $50 \%$ inhibition of $\mathrm{CN}$ activity compared to controls, despite a mean

Address correspondence to Phillip F. Halloran, University of Alberta, \#205 8249-114 Street, Edmonton, Alberta T6G 2R8, Canada. Phone: 403-492-8880; FAX: 403-431-0461; E-mail:phil.halloran@ualberta.ca.

Received for publication 22 February 1995 and accepted in revised form 11 May 1995.

1. Abbreviation used in this paper: $\mathrm{CN}$, calcineurin; $\mathrm{CsA}$, cyclosporine A; CyP, cyclophillin; PGP, P glycoprotein; RBC, red blood cell.

J. Clin. Invest.

(C) The American Society for Clinical Investigation, Inc.

0021-9738/95/09/1254/07 \$2.00

Volume 96, September 1995, 1254-1260
CsA concentration ( $180 \mu \mathrm{g} / \mathrm{ml}$ ) that would be completely inhibitory in vitro (7). With partial inhibition of $\mathrm{CN}$ activity, small changes in CsA availability in lymphocytes may lead directly to fluctuations in $\mathrm{CN}$ inhibition. Inhibition of $\mathrm{CN}$ activity prevents the calcium-dependent activation of transcription factors such as NFAT $_{p}$ and NFAT $(8-10)$ and in some circumstances NF- $\kappa$ B (11), which are crucial to the induction of cytokines during $T$ cell activation $(4,12-16)$.

Despite increasing information about the mechanism of CsA inhibition, little is known about the mechanism of recovery from CsA. The question is important because recovery kinetics are the key to understanding immunosuppression recovery in CsA-treated patients. Using $\mathrm{CN}$ activity as the measure of CsA effect, we investigated recovery of PBL from CsA. In PBL from renal transplant patients receiving chronic CsA therapy, $\mathrm{CN}$ activity quickly recovered after a single oral dose of CsA, concomitant with falling CsA blood levels. In vitro, recovery of $\mathrm{CN}$ activity was associated with CsA efflux from PBL. We identified at least two mechanisms for CsA efflux, both of which depend on the equilibration of intracellular CsA with the total (intracellular + extracellular) pool. Thus changes in CsA availability have rapid functional consequences at the level of lymphocyte $\mathrm{CN}$ activity, implying that stability and predictability of CsA kinetics are important to stable clinical immunosuppression.

\section{Methods}

Patients. As part of an Institutional Review Board-approved study involving CsA pharmacokinetics, stable renal transplant patients had blood drawn for measurement of CsA blood level and PBL CN activity. Each patient was receiving chronic immunosuppressive therapy with CsA (Neoral), azathioprine, and corticosteroids. Each patient was clinically stable at the time of study, and gave informed consent. CsA was measured by fluorescence polarization (Abbott TDx; Abbott Diagnostics, Abbott Park, IL) as described (17).

Cells. PBL mononuclear cells were isolated from whole blood of patients or healthy controls by Ficoll-Hypaque gradient centrifugation of buffy coat. CCRF-CEM is a human leukemic lymphoblast cell line; CEM/VLB 100 is derived from CCRF-CEM and is distinguished by the ability to grow in the presence of $100 \mathrm{ng} / \mathrm{ml}$ vinblastine, a concentration toxic to CCRF-CEM (18). This is due to up-regulation of surface $P$ glycoprotein (PGP) molecules. Cell lines are thus designated "PGP low" (CCRF-CEM) and "PGP high" (CEM/VLB $\left.{ }_{100}\right)$. Both lines were generously supplied by Dr. L. Pilarski (Dept. of Immunology, University of Alberta, Edmonton, Canada).

Cells were suspended in medium RPMI 1640 (GIBCO BRL, Burlington, Canada) supplemented with $10 \%$ pooled human serum (NABI, Miami, FL) for PBL or FCS (GIBCO BRL) for cell lines. Cells were incubated in CsA for $30 \mathrm{~min}$ (PBL $=5-10 \times 10^{6}$ cells $/ \mathrm{ml}$; cell lines $=1-2 \times 10^{6}$ cells $/ \mathrm{ml}$ ), washed twice in cold PBS and resuspended at a final concentration of $5 \times 10^{6} \mathrm{cells} / \mathrm{ml}(\mathrm{PBL})$ or $1 \times 10^{6} \mathrm{cells} / \mathrm{ml}$ (cell lines). For PGP inhibition studies, verapamil and quinidine were purchased from Sigma Chemical Co. (St. Louis, MO).

Cyclosporine A. Cyclosporine A (kindly provided by Dr. G. Murphy, Sandoz Canada Inc., Dorval, Quebec) was prepared according to Sandoz 
guidelines: $28 \mathrm{mg}$ of CsA powder plus $1 \mathrm{ml}$ of $99 \%$ ethanol plus 0.4 $\mathrm{ml}$ of Tween 80 (Fisher Scientific Co., Fairlawn, NJ) was mixed to produce a stock solution of 20 grams/liter. In all experiments, the concentrations of CsA solvent was kept constant in all groups ( 0.35 $\times 10^{-3} \%$ ethanol and $0.14 \times 10^{-3} \%$ Tween 80 ). $\left[{ }^{3} \mathrm{H}\right] \mathrm{CsA}$ tracer (final sp act $\sim 0.25 \mathrm{mCi} / \mu$ mole) was used (kindly provided by Dr. R. W. Yatscoff, Department of Laboratory Medicine \& Pathology, University of Alberta, Edmonton, Canada).

Phosphatase measurement. CN activity was measured in cell lysates as described by Fruman et al. (19) with minor modifications. Briefly, cell lysates were assessed for the ability to dephosphorylate a ${ }^{32} \mathrm{P}$-serine labeled 19 amino acid substrate in the presence of $500 \mathrm{nM}$ okadaic acid. Okadaic acid inhibits phosphatases PP1C and PP2A, so that in these experimental conditions, ${ }^{32} \mathrm{P}$ release reflects the phosphatase activity of both CN (PP2B), which is CsA sensitive, and PP2C, which is resistant to both okadaic acid and CsA. PP2C accounts for 10-20\% of total phosphatase activity in PBL (Batiuk T. D., F. Pazderka, J. Enns, L. DeCastro, and P. F. Halloran, unpublished data) in this assay and represents stable background activity. $\mathrm{CN}$ (i.e., CsA sensitive) phosphatase activity is $>90 \%$ inhibited by CsA $100 \mu \mathrm{g} / 1$ in vitro and is completely inhibited at $1,000 \mu \mathrm{g} / \mathrm{l}$. Thus for in vitro experiments, residual phosphatase activity after CsA exposure is largely due to PP2C. Patient results show $\mathrm{CN}$ activity and represent the phosphatase activity after subtraction of PP2C activity, defined as activity in the presence of CsA $1,000 \mu \mathrm{g}$ / 1 added in vitro. Patient measurements were carried out on different occasions. On each occasion, control $\mathrm{CN}$ values were calculated in PBL from at least three healthy volunteers. $\mathrm{CN}$ activity was calculated based on cpm of ${ }^{32} \mathrm{P}$-released (background) and corrected for cell input number.

IFN- $\gamma$ measurement. PBL were stimulated with either murine antiCD3 (OKT3; Ortho Diagnostics Systems Inc., Raritan, NJ) $1 \mathrm{ng} / \mathrm{ml}$ for $18 \mathrm{~h}$ or calcium ionophore A23187 0.5-5 $\mu \mathrm{M}$ (as indicated) for 4 h. IFN- $\gamma$ was measured in culture supernatants by ELISA (Biosource International, Camarillo, TX).

Recovery. Red blood cells (RBC) were isolated from whole blood after centrifugation and removal of the buffy coat (used for PBL isolation). Under recovery conditions involving RBC, CsA pretreated PBL were washed, resuspended at $10 \times 10^{6} \mathrm{cells} / \mathrm{ml}$, and diluted $1: 1(\mathrm{vol} /$ vol) with packed RBC. RBC concentrations indicate dilutions starting with concentrated RBC. Thus 1:1 indicates 1 vol PBL and 1 vol of undiluted RBC (i.e., final concentration of $5 \times 10^{6} \mathrm{PBL} / \mathrm{ml}$ and hematocrit $=50 \%), 1: 2$ indicates one vol PBL with one vol of RBC diluted one in two (i.e., hematocrit $=25 \%$ ), etc. After recovery with $\mathrm{RBC}$, PBL were reisolated by Ficoll-Hypaque centrifugation as before. RBC contain some "contaminating" PBL that may be included in the final sample, but due to size differences between cell lines and PBL, we have determined the maximum contamination to be $2 \%$ of the total final cell number. Some recovery experiments utilized anti-CsA antibody $(8.8 \mu \mathrm{g} / \mathrm{ml})$, kindly provided by Dr. Max Schreier (Sandoz AG, Basel, Switzerland). The cells in these experiments were washed twice before lysis.

Statistics. Data on bar graphs shown as mean \pm SEM. Comparison between treatment groups was performed using unpaired Student's $t$ test.

\section{Results}

The relationship between CsA level and $C N$ activity in patients. We first determined the relationship between CsA blood level and $\mathrm{CN}$ activity in patients. In four renal transplant patients taking CsA (Neoral) every $12 \mathrm{~h}$, blood was drawn immediately before a usual dose of CsA, and 1, 2, and $4 \mathrm{~h}$ afterwards. Fig. 1 shows that in each case there was a rapid increase in CsA blood levels followed by a more gradual decline. Inhibition of $\mathrm{CN}$ activity showed a similar trend, however, the pattern of recovery of $\mathrm{CN}$ activity was more variable. The variable degree

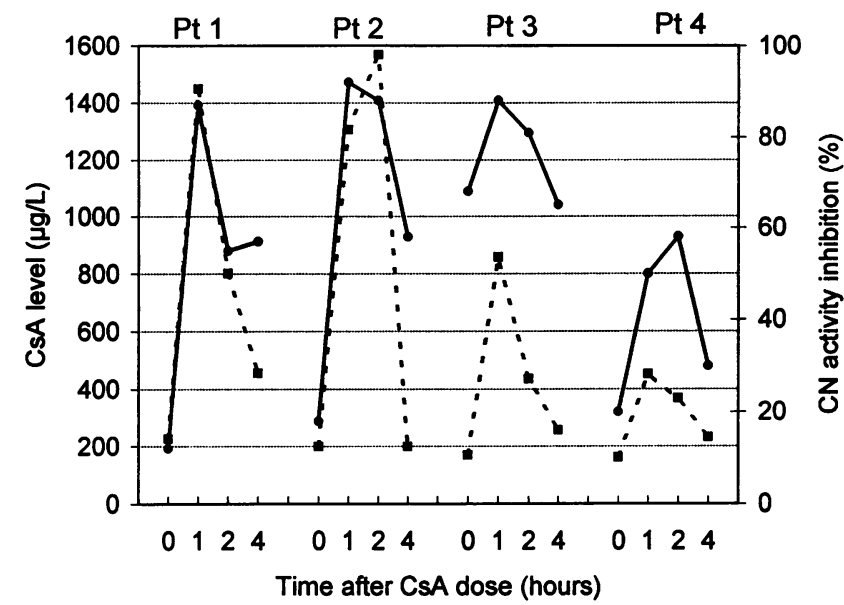

$-\cdots$ CsA level $\rightarrow$ CN activity inhibition

Figure 1. CsA blood levels and $\mathrm{CN}$ activity inhibition curves in PBL of CsA-treated patients after a single dose of CsA. CsA level and CN activity were determined in each of four patients immediately prior to (Time $=0$ ), and 1,2 , and $4 \mathrm{~h}$ after a usual oral CsA dose. $\mathrm{CN}$ activity is displayed as percent inhibition compared to $\mathrm{CN}$ activity measured concomitantly in normal controls (see Methods).

of inhibition of $\mathrm{CN}$ activity seen predose (Time $=0$ ), and its weak correlation with CsA blood level, were similar to our previous findings (7) and those of Pai et al. (20).

Recovery in vitro is aided by extracellular binding sites. To study the characteristics of recovery from CsA, we first studied the characteristics of CsA inhibition of CN activity in PBL in vitro. We have shown that when PBL are exposed to CsA for at least $30 \mathrm{~min}, 50 \%$ inhibition (i.e., the $\mathrm{IC}_{50}$ ) of $\mathrm{CN}$ activity occurs at CsA concentrations of $\sim 10-15 \mu \mathrm{g} / \mathrm{liter}$ and $85 \%$ + inhibition occurs at $100 \mu \mathrm{g} / \mathrm{liter}(7)$. The time course of inhibition was studied by exposing $5 \times 10^{6} \mathrm{PBL} / \mathrm{ml}$ to CsA $100 \mu \mathrm{g} /$ liter. The maximum degree of inhibition of $\mathrm{CN}$ activity was seen by $10 \mathrm{~min}$, with $>80 \%$ of maximum inhibition having occurred by $1 \mathrm{~min}$, the shortest time point measurable. In contrast to this rapid "on" rate of CsA effect, when PBL exposed to CsA in vitro were washed and resuspended in CsA-free culture medium, recovery of $\mathrm{CN}$ activity was poor, although with some variability, even after $24 \mathrm{~h}$ (Table I). The degree of recovery of $\mathrm{CN}$ activity was $0-20 \%$ after exposure to CsA concentrations of $10 \mu \mathrm{g} /$ liter. Even at CsA $1 \mu \mathrm{g} /$ liter, maximum recovery was only $50 \%$ after $24 \mathrm{~h}$. Thus in vitro CsA inhibition of $\mathrm{CN}$ activity has a very rapid on rate, but a very slow off rate.

We reasoned that a possible explanation for the limited recovery was a lack of a sufficient number of extracellular CsA binding sites to prevent immediate reentry of CsA. To examine the effect of potential extracellular CsA binding sites, we tested whether the addition of RBC to the recovery medium would affect recovery of $\mathrm{CN}$ activity in cells pretreated with CsA $100 \mu \mathrm{g} /$ liter (Fig. 2). We also tested whether recovery was dependent on protein synthesis using the protein synthesis inhibitor cycloheximide $(50 \mu \mathrm{g} / \mathrm{ml})$. Before measurement of $\mathrm{CN}$ activity, the RBC were removed by Ficoll centrifugation. This step does not affect recovery (7). Contaminating RBC accounted for $<2 \%$ of the final total cell count. After $4 \mathrm{~h}$, there was $1 \%$ recovery of $\mathrm{CN}$ activity in medium alone. The addition of $\mathrm{RBC}$ increased the recovery of $\mathrm{CN}$ activity in a dose-depen- 
Table I. Recovery of CN Activity after Inhibition by CsA

\begin{tabular}{crrrr}
\hline Experiment & CsA* & Inhibition $^{\ddagger}$ & Time $^{8}$ & Recovery \\
\hline & $\mu g /$ liter & $\%$ & $h$ & $\%$ \\
1 & 1 & 37 & 16 & 18 \\
& 10 & 88 & 16 & 0 \\
& 100 & 99 & 16 & 0 \\
2 & 1,000 & 100 & 16 & 0 \\
& 1 & 20 & 24 & 50 \\
& 10 & 23 & 24 & 0 \\
& 100 & 93 & 24 & 16 \\
3 & 1,000 & 100 & 24 & 5 \\
& 40 & 95 & 4 & 17 \\
4 & 200 & 100 & 4 & 12 \\
5 & 100 & 94 & 2 & 1 \\
6 & 100 & 88 & 4 & 20 \\
7 & 100 & 92 & 4 & 9 \\
8 & 100 & 92 & 4 & 0 \\
& 500 & 100 & 3 & 19
\end{tabular}

* PBL were incubated for $1 \mathrm{~h}$ in medium with CsA concentration indicated, washed, and resuspended in CsA-free medium. ${ }^{\ddagger}$ Percent inhibition $=\mathrm{CN}$ activity inhibition as a percentage of maximum inhibitiable $\mathrm{CN}$ activity. ${ }^{\S}$ Time $=$ number of hours cells were resuspended in CsAfree medium. "Recovery shown as degree of $\mathrm{CN}$ recovery as a percentage of total possible recovery.

dent manner, to a maximum of $50 \%$. Recovery was not affected by cycloheximide. Similar enhancement of $\mathrm{CN}$ recovery could be achieved using anti-CsA Ab instead of RBC (data not shown).

Recovery of cytokine production parallels recovery of $\mathrm{CN}$ activity. To investigate the functional consequences of $\mathrm{CN}$ recovery, we studied the recovery of the ability to produce IFN$\gamma$ after stimulation by either calcium ionophore (A23187) or

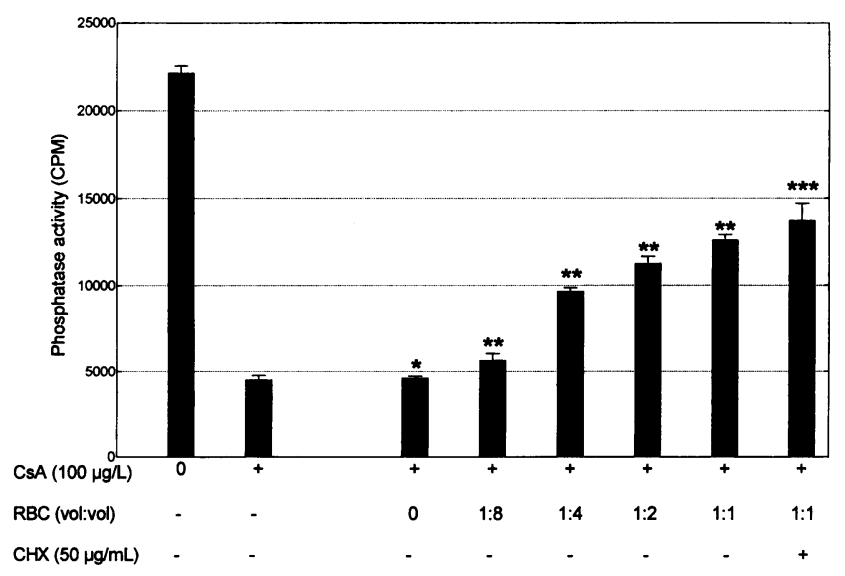

Figure 2. Effect of untreated $\mathrm{RBC}$ on the recovery of $\mathrm{CN}$ activity in CsA-treated PBL. PBL were treated as indicated with CsA in vitro for $1 \mathrm{~h}$, washed, and resuspended in medium $+\mathrm{RBC}$ as indicated for $4 \mathrm{~h}$. $\mathrm{RBC}$ dilutions are as described in Methods. Cycloheximide ( $\mathrm{CHX}$ ) was added, as indicated, before CsA treatment and maintained at $50 \mu \mathrm{g} / \mathrm{ml}$ throughout the experiment. $* P=$ NS compared to CsA-treated group before recovery; $* * P \geq 0.05$ compared to preceding group; $* * * P=$ NS compared to preceding group.
Table II. Recovery of IFN- $\gamma$ Production after Inhibition by CsA

\begin{tabular}{ccccc}
\hline Experiment & CsA $^{*}$ & Time $^{\ddagger}$ & \multicolumn{1}{c}{ Stimulus $^{8}$} & Recovery" \\
\hline & $\mu g /$ iter & & & $\%$ \\
1 & 200 & $5 \mathrm{~h}$ & A23187 $0.5 \mu \mathrm{M}$ & 4 \\
& & $8 \mathrm{~h}$ & A23187 $0.5 \mu \mathrm{M}$ & 0 \\
2 & 200 & $5 \mathrm{~h}$ & $\mathrm{~A} 231875 \mu \mathrm{M}$ & 8 \\
3 & 200 & $5 \mathrm{~h}$ & $\mathrm{~A} 231875 \mu \mathrm{M}$ & 30 \\
4 & 100 & $8 \mathrm{~h}$ & A23187 $5 \mu \mathrm{M}$ & 0 \\
5 & 100 & $19 \mathrm{~h}$ & OKT3 $10 \mathrm{ng} / \mathrm{ml}$ & 15 \\
\hline
\end{tabular}

* PBL were incubated for $1 \mathrm{~h}$ in medium with CsA concentration indicated, washed, and resuspended in CsA-free medium. ${ }^{\ddagger}$ Time $=$ number of hours cells were resuspended in CsA-free medium. ${ }^{\S}$ A23187 was added for final $4 \mathrm{~h}$ of recovery period; OKT3 was added for the final $18 \mathrm{~h}$. "Recovery shown as proportion of IFN- $\gamma$ produced as a percentage of baseline control; CsA-treated cells made no IFN- $\gamma$ when stimulated in presence of indicated concentration of CsA.

anti-CD3 mAb (OKT3) (Table II). As with CN activity, the recovery of production of IFN- $\gamma$ by cells pretreated with CsA 100 or $200 \mu \mathrm{g} /$ liter was limited in culture medium alone with a range of $0-30 \%$ recovery at times up to $19 \mathrm{~h}$. We then determined if recovery of IFN- $\gamma$ production correlated with recovery of CN activity. PBL were treated with CsA $100 \mu \mathrm{g} /$ liter, washed, and recovered in the presence of increasing dilutions of RBC for $4 \mathrm{~h}$ (Table III). RBC were removed and PBL were lysed for measurement of $\mathrm{CN}$ activity, or suspended in medium and stimulated overnight with OKT3 $10 \mathrm{ng} / \mathrm{ml}$ and supernatant then assayed for IFN- $\gamma$. As shown in Table III, recovery of IFN- $\gamma$ production mirrored the recovery of $\mathrm{CN}$ activity, indicating that recovery of $\mathrm{CN}$ activity has immediate functional consequences. (As a positive control for the effect of cycloheximide on protein synthesis, $\mathrm{CN}$ recovery was not inhibited by cycloheximide $50 \mu \mathrm{g} / \mathrm{ml}$ whereas IFN- $\gamma$ production was completely blocked.)

CsA efflux is temperature dependent. To track CsA movement $\left[{ }^{3} \mathrm{H}\right] \mathrm{CsA}(100 \mu \mathrm{g} /$ liter $)$ treated PBL were washed and incubated with medium or RBC for $2 \mathrm{~h}$ at either 37 or $4^{\circ} \mathrm{C}$ (Fig. 3 ). While some recovery ( $8 \% \mathrm{P} \leq 0.005$ compared to baseline) occurred in culture medium alone at $37^{\circ} \mathrm{C}$, it was markedly enhanced in the presence of $\mathrm{RBC}(54 \%, P \leq 0.0001)$. No recovery was seen at $4^{\circ} \mathrm{C}$, even in the presence of RBC $(P=\mathrm{NS}$ for both groups compared to baseline). As shown, the concentration of $\left[{ }^{3} \mathrm{H}\right] \mathrm{Cs} A$ in $\mathrm{PBL}$ varied inversely with $\mathrm{CN}$ activity.

Table III. Parallel (RBC facilitated) Recovery of CN Activity and IFN- $\gamma$ Production after CsA Treatment*

\begin{tabular}{lcccc}
\hline & $\begin{array}{c}\text { Before } \\
\text { recovery }\end{array}$ & \multicolumn{3}{c}{$\begin{array}{c}\text { Degree of recovery } \\
\text { (\% of maximum possible) } \\
\text { Recovery conditions }\end{array}$} \\
\hline \\
CN activity & $0 \pm 1^{\S}$ & $20 \pm 3$ & $33 \pm 8$ & $49 \pm 6$ \\
IFN- $\gamma$ production & $0 \pm 1$ & $16 \pm 1$ & $31 \pm 3$ & $39 \pm 5$
\end{tabular}

* PBL treated with CsA $100 \mu \mathrm{g} /$ liter for $1 \mathrm{~h}$, washed twice, and resuspended in medium with increasing concentrations of RBC. ${ }^{\ddagger}$ Ratio of PBL:RBC. ${ }^{\S}$ Mean \pm SEM, $n=3$ in all groups. 


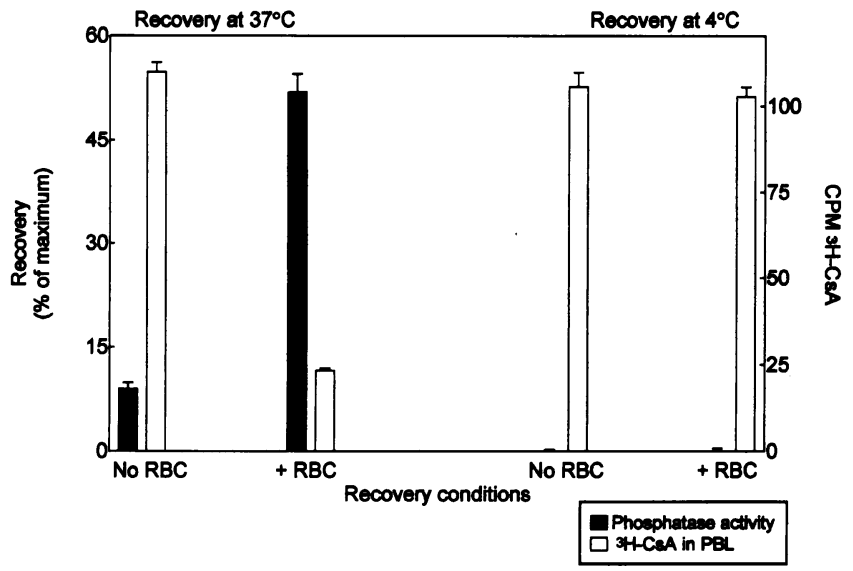

Figure 3. Effect of temperature on recovery of $\mathrm{CN}$ activity and on $\left[{ }^{3} \mathrm{H}\right] \mathrm{Cs} A$ movement. PBL were treated with $\left[{ }^{3} \mathrm{H}\right] \mathrm{CsA} 100 \mu \mathrm{g} /$ liter for $1 \mathrm{~h}$, washed, and resuspended in medium with RBC (1:1 dilution) for $2 \mathrm{~h}$ at 37 or $4^{\circ} \mathrm{C}$. Recovery shown as percentage of maximum possible recovery of $\mathrm{CN}$ activity; $\left[{ }^{3} \mathrm{H}\right] \mathrm{CsA}$ reflects cpm in $10^{6}$ cells.

Role of $P$ glycoprotein. The temperature dependence of CsA efflux and CN recovery suggested that CsA is transported out of cells by an energy-dependent mechanism. PGP, the product of the $m d r l$ gene, transports hydrophobic drugs, including CsA (21), out of cells. We tested the effect of CsA on CN activity in two human $\mathrm{T}$ cell leukemia lines that differ only in PGP expression (PGP-low vs PGP-high; Fig. 4). CsA $100 \mu \mathrm{g} /$ liter inhibited CN activity less in PGP-high cells than PGP-low cells $(P \leq 0.002)$. After $2 \mathrm{~h}$ in culture medium alone (no RBC), PGP-high cells showed recovery of $58 \%$ of $\mathrm{CN}$ activity compared to only $8 \%$ in the PGP-low cells $(P \leq 0.0005)$.

To study the minimum time necessary for recovery of $\mathrm{CN}$ activity, PGP high cells were treated with CsA, washed, and suspended in cold $\left(4^{\circ} \mathrm{C}\right)$ medium at $10 \times 10^{6}$ cells $/ \mathrm{ml}$. They were brought to $37^{\circ} \mathrm{C}$ by 10 times dilution with warm $\left(37^{\circ} \mathrm{C}\right)$

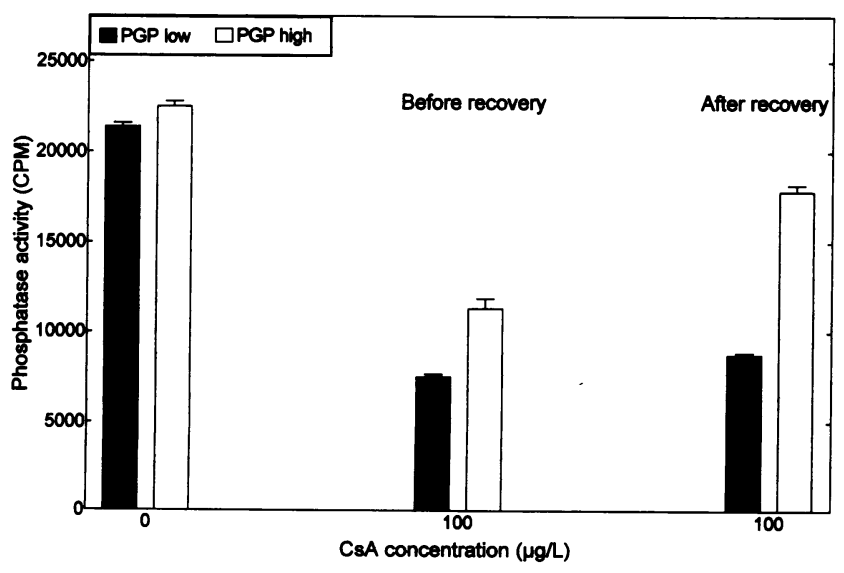

Figure 4. Effect of CsA on $\mathrm{CN}$ activity in cells with low or high expression of PGP. Cell lines differing only in surface PGP expression (see Methods) were assayed for phosphatase activity in the absence of CsA, immediately after exposure to CsA $100 \mu \mathrm{g} /$ liter for $1 \mathrm{~h}$ (Before recovery) and after being removed from CsA, washed, and resuspended in CsA-free medium for $1 \mathrm{~h}$ (After recovery).

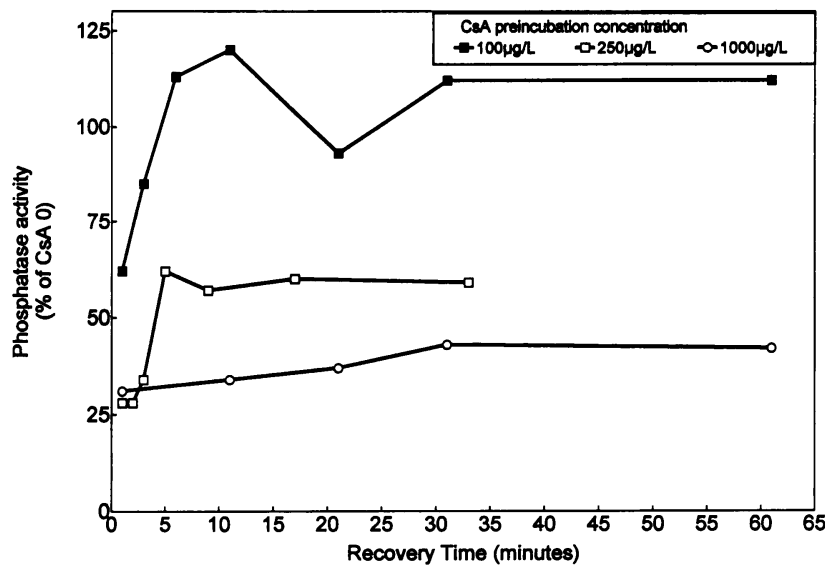

Figure 5. Time course of CN recovery in PGP-high cells. PGP-high cells were preincubated with CsA as indicated, washed in cold medium, and brought up to $37^{\circ} \mathrm{C}$ (see Methods). Cells were assayed for phosphatase activity at the times indicated.

medium and incubated in a $37^{\circ} \mathrm{C}$ water bath for the times indicated (Fig. 5). The rate of recovery for cells treated with CsA 100 or $250 \mu \mathrm{g} /$ liter was initially rapid, with significant recovery seen within 2 min ( $P \leq 0.05$ for both), with the final degree of recovery usually seen by $5 \mathrm{~min}$. Surprisingly, recovery was incomplete in the CsA 250 and 1,000 $\mu \mathrm{g} /$ liter groups. As with PBL, no recovery was seen when PGP-high cells pretreated with CsA $100 \mu \mathrm{g} /$ liter were incubated at $4^{\circ} \mathrm{C}$ (data not shown).

Effect of PGP inhibition on recovery of $C N$ activity. We sought to confirm the role of PGP in the rapid recovery of PGP-high cells by specifically inhibiting PGP transport of CsA. Verapamil and quinidine were chosen as they have been shown to inhibit PGP transport of CsA out of tumor cell lines (21). To confirm effective inhibition of PGP transport, PGP-high cells were incubated overnight with verapamil or quinidine (both at $100 \mu \mathrm{M}$, based on [21]) in vinblastine-containing medium. This resulted in $>90 \%$ cell death (by dye exclusion) by either agent, indicating effective inhibition of PGP transport of vinblastine.

We then evaluated the effect of blockade of PGP transport on the recovery of cells from the effects of CsA. PGP-high cells were incubated with verapamil or quinidine (at $100 \mu \mathrm{M}$ ) in vinblastine-free medium before CsA exposure (Fig. 6). Preincubation with either agent led to a greater degree of $\mathrm{CN}$ activity inhibition by CsA $(P \leq 0.0005)$. Recovery of $\mathrm{CN}$ activity was completely prevented by either agent when cells were resuspended in CsA-free medium.

While PGP blockade prevented recovery of PGP-high cells in medium alone, we then determined if PGP blockade affected recovery in the presence of $\mathrm{RBC}$ and anti-CsA $\mathrm{Ab}$, as is required for PBL recovery. To test this, verapamil pretreated PGP-high cells were exposed to CsA $100 \mu \mathrm{g} /$ liter, washed, and resuspended (Fig. 7). The addition of anti-CsA Ab facilitated $17 \%$ recovery $(P \leq 0.05$ compared to medium alone). When RBC were present in the recovery medium, recovery was $71 \%$ $(P \leq 0.0005$ compared to either medium alone or anti-CsA $\mathrm{Ab})$. Recovery in the presence of PGP blockade thus indicates a separate, PGP-independent mechanism for CsA efflux. The relative contribution of each mechanism could not be determined with certainty in PGP-high cells because of the extremely rapid recovery seen with uninhibited PGP (Fig. 5). 


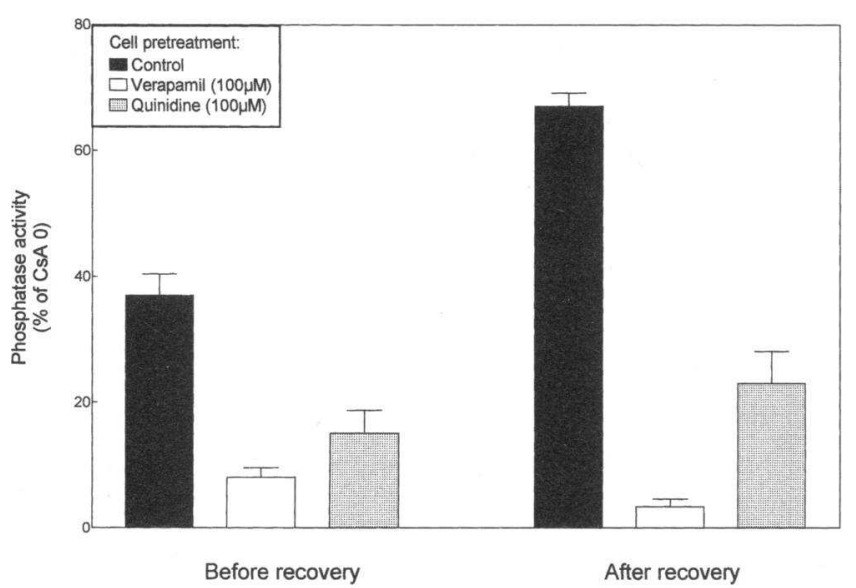

Figure 6. Effect of competitive PGP substrates on CsA transport by PGP in PGP-high cells. PGP-high cells were pretreated for $1 \mathrm{~h}$ as indicated. After 1-h exposure to CsA $100 \mu \mathrm{g} /$ liter, phosphatase activity was measured before (Before recovery) and after removal from CsA and resuspension in CsA-free medium for $1 \mathrm{~h}$ (After recovery).

To determine if PGP activity was an important factor in CsA-treated PBL, we measured the effect of PGP blockade, by verapamil $(100 \mu \mathrm{M})$, on CsA inhibition of $\mathrm{CN}$ in PBL (Fig. 8). Over a wide CsA concentration range, CsA inhibition of $\mathrm{CN}$ activity was not altered in PBL pretreated with verapamil $100 \mu \mathrm{M}$ compared to PBL exposed to verapamil solvent. Furthermore, in PBL exposed to CsA $100 \mu \mathrm{g} /$ liter, washed and resuspended (Table IV), RBC or anti-CsA antibody-assisted recovery of $\mathrm{CN}$ activity was unaffected by verapamil pretreatment, confirming the existence of a PGP-independent efflux mechanism.

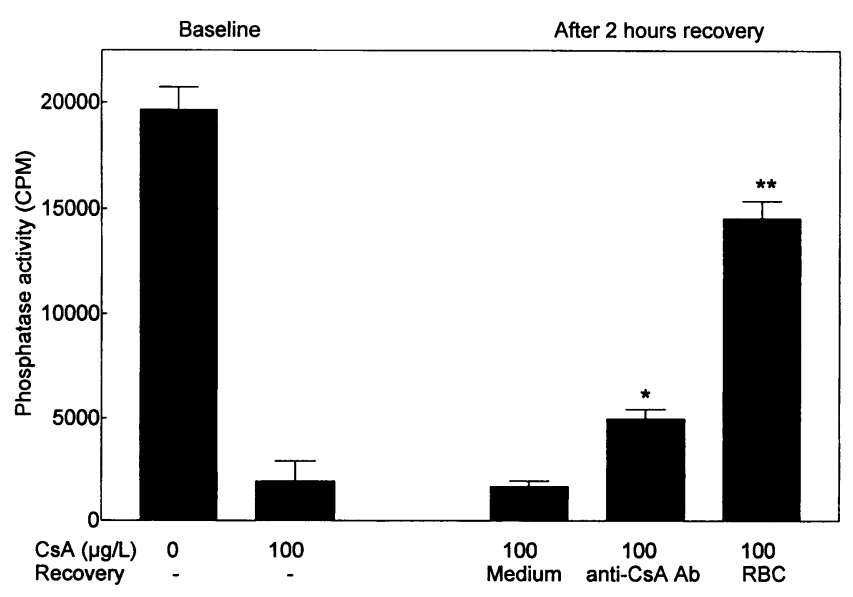

Figure 7. Effect of verapamil on anti-CsA Ab or RBC-facilitated recovery of CN activity in PGP-high cells. PGP-high cells were exposed to verapamil $100 \mu \mathrm{M}$ throughout the experiment starting $1 \mathrm{~h}$ before exposure to CsA solvent (CsA $O$ ) or CsA for $1 \mathrm{~h}$. Phosphatase activity was measured in the presence of CsA or solvent (Baseline) and, in CsAtreated cells, $2 \mathrm{~h}$ after removal from CsA and resuspension in medium alone, medium containing anti-CsA Ab $(8.8 \mu \mathrm{g} / \mathrm{ml})$, or medium containing $\operatorname{RBC}(1: 1$ dilution $){ }^{*} P \leq 0.002$ compared to medium alone; $* * P \leq 0.0005$ compared to both medium alone and medium + antiCsA Ab.

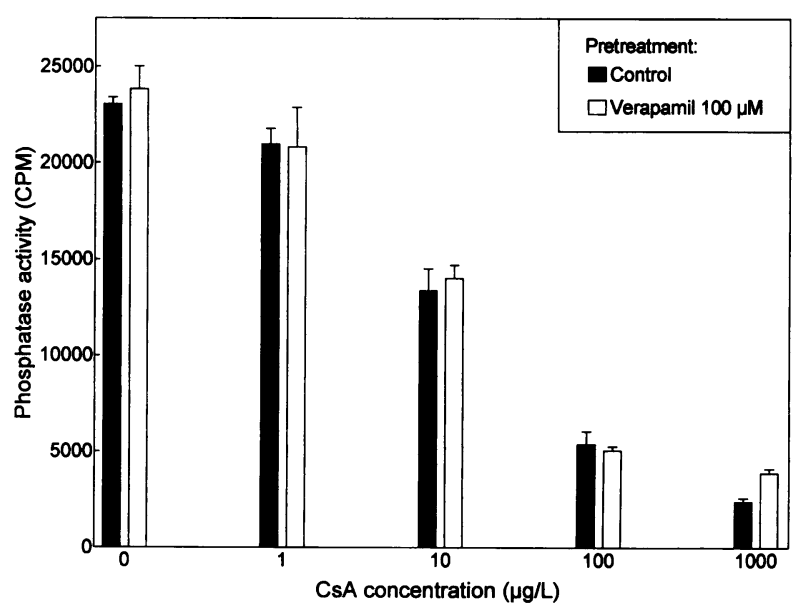

Figure 8. Effect of verapamil on CsA inhibition of $\mathrm{CN}$ activity in PBL. PBL were exposed to either verapamil $100 \mu \mathrm{M}$ or verapamil solvent (water) throughout the experiment starting $1 \mathrm{~h}$ before exposure to CsA (concentrations as indicated). Phosphatase measurement was performed after 1-h exposure to CsA.

\section{Discussion}

We have shown that CsA inhibition of $\mathrm{CN}$ activity in PBL of CsA-treated transplant patients is rapidly reversible. In vitro, recovery of $\mathrm{CN}$ activity does not require protein synthesis, is temperature dependent, and is associated with CsA efflux from the cells. At least two mechanisms of efflux were identified. One mechanism involved rapid, PGP-dependent efflux, but this was only demonstrable in a cell line expressing high levels of PGP. PBL utilized a slower, PGP-independent efflux mechanism that required the addition of extracellular binding sites. Thus movement down concentration gradients appears to be obligatory for net CsA movement out of PBL. Rapid CsA equilibration in the large reservoir of binding sites found in vivo will have direct and rapid consequences on CsA inhibition of lymphocyte $\mathrm{CN}$ activity.

While rapid inhibition of $\mathrm{CN}$ activity by CsA was not surprising, rapid recovery in patients was unexpected. CsA inhibition of $\mathrm{T}$ lymphocyte activation is the result of the formation of a trimolecular complex in a sequence of two reactions that can be depicted as:

\section{$\mathrm{CsA}+\mathrm{CyP} \stackrel{1}{=} \mathrm{CsA}-\mathrm{CyP}+\mathrm{CN} \stackrel{2}{=} \mathrm{CsA}-\mathrm{CyP}-\mathrm{CN}$}

with the final complex resulting in inhibition of $\mathrm{CN}$ activity.

Table IV. The Effect of Verapamil on the Degree of Recovery of CN Activity in PBL

\begin{tabular}{lccc}
\hline & \multicolumn{3}{c}{ Degree of recovery (\% of maximum possible) } \\
\cline { 2 - 4 } \multicolumn{1}{c}{ Pretreatment } & Culture medium & $\begin{array}{c}\text { Recovery conditions } \\
\text { Anti-CsA Ab }\end{array}$ & RBC \\
\hline & & $8.8 \mu g / m l$ & $1: 1$ dilution \\
No verapamil & $0 \pm 1 \%$ & $35 \pm 2 \%$ & $36 \pm 4 \%$ \\
Verapamil $100 \mu \mathrm{M}$ & $0 \pm 0 \%$ & $26 \pm 1 \%$ & $43 \pm 3 \%$ \\
\hline
\end{tabular}

$P \leq 0.001$ compared to medium alone group within the same verapamil treatment group. 
Both reactions have strong binding constants $(22,23)$, and in PBL in vitro these reactions took place within minutes. In patients, the kinetics of $\mathrm{CN}$ activity inhibition were the same as those for CsA blood level, supporting rapid CsA influx and CsA-CyP-CN complex formation. Of considerable interest, however, was the speed with which both reactions reversed in vivo (i.e., moved right to left). The rapid rate and the in vitro recovery in the presence of protein synthesis inhibition indicate that recovery of $\mathrm{CN}$ activity was due to dissociation of the CsACyP-CN complex.

Dissociation of the complex is due to net loss of CsA from the cells. Ryffel et al. (24) showed that covalently binding CsA within cells prevented the recovery (produced in control cells by vigorous washing with anti-CsA $\mathrm{Ab}$ ) of their ability to proliferate and produce IL-2. We have shown that net CsA efflux, measured by decreased cellular $\left[{ }^{3} \mathrm{H}\right] \mathrm{CsA}$ content, coincided with the recovery of $\mathrm{CN}$ activity. Together the data indicate that CsA efflux from cells is the rate-limiting step in their recovery. In our study, the increased rate of recovery that occurred in vitro with the addition of anti-CsA Ab or RBC suggests that usual culture medium conditions do not provide sufficient CsA binding sites to permit net CsA efflux. The patient data show that even at therapeutic CsA blood concentrations, there were sufficient extralymphocytic binding sites to permit net efflux. The in vitro consequence of CsA efflux and recovery of CN activity was the recovery of inducible IFN- $\gamma$ synthesis; the in vivo consequence would therefore be the return of immunocompetence. This may contribute to the relatively high rate of acute rejection seen in transplant patients who discontinue CsA therapy $(25,26)$.

There are at least two independent, temperature-sensitive mechanisms for CsA efflux: PGP dependent and PGP independent. PGP-dependent recovery was demonstrated in a cell line with high expression of surface PGP. In these cells, recovery of $\mathrm{CN}$ activity occurred within minutes in culture medium alone and could be blocked by competetive PGP substrates. PGP presumably facilitated recovery by pumping CsA out of the cells up a concentration gradient. However, when PGP-high cells were pretreated with CsA $250 \mu \mathrm{g} /$ liter or $1,000 \mu \mathrm{g} /$ liter, recovery of $\mathrm{CN}$ activity was incomplete $(250 \mu \mathrm{g} /$ liter $)$ or did not occur $(1,000 \mu \mathrm{g} /$ liter $)$. There are two possible explanations for these data. First is that high CsA concentrations impaired PGP function. The early and rapid recovery seen in the cells pretreated with CsA $250 \mu \mathrm{g} /$ liter make this unlikely. The second, and more likely, possibility is that culture medium contains a limited number of potential CsA binding sites that become quickly saturated. The subsequent CsA influx-efflux equilibrium does not permit the net CsA efflux necessary for recovery of $\mathrm{CN}$ activity.

PBL recovery in vitro involves a PGP-independent mechanism. Existence of such a mechanism is evident by our findings, in both PBL and PGP-high cells, that inhibition by verapamil of PGP-mediated transport of CsA did not prevent recovery when cells were resuspended in the presence of RBC or antiCsA antibody. At least one non-PGP-mediated, energy-dependent drug transport mechanism has been identified in tumor cell lines $(27,28)$. However the ability to transport CsA and the in vivo distribution have not yet been demonstrated for this pump. It is also possible that CsA is not actively transported, but leaves the cells by simple diffusion, which may be impaired at $4^{\circ} \mathrm{C}$ because of either changes in membrane fluidity and/or microtubule depolymerization. Alternatively, uptake by the carrier
(RBC) may be impaired at low temperatures. The PGP-independent mechanism likely predominates in vivo as PGP is expressed at relatively low levels in $\operatorname{PBL}(29,30)$.

In vivo, $\mathrm{CsA}$ inhibition of $\mathrm{CN}$ activity is rapid; recovery can also occur very quickly. While the kinetics of recovery in vivo will be better understood with the completion of ongoing studies, the current in vitro data allow us to propose the following basic model for the kinetics of CsA immunosuppression: (a) CsA inhibits CN activity in PBL quickly, i.e., CsA has a rapid "on" rate; $(b)$ Recovery of $\mathrm{CN}$ activity (and hence of the ability to make IFN- $\gamma$ ) can occur within minutes in PGPhigh cells, indicating the "off" rate to be potentially as fast as the "on" rate; $(c)$ Net efflux of CsA from the cells is the ratelimiting step for the recovery of $\mathrm{CN}$ activity; and $(d)$ In cells with low PGP activity, exemplified by PBL, net CsA efflux requires extracellular binding sites. In culture medium alone, binding sites are insufficient; extracellular hydrophobic binding sites facilitated significant recovery (up to $50 \%$ at $4 \mathrm{~h}$ ). However, this recovery is still incomplete. If diffusion into the hydrophobic environment of cell membranes was sufficient for CsA equilibration, the excess of $\mathrm{RBC}(\sim 1,000$ times more $\mathrm{RBC}$ than $\mathrm{PBL}$ ) would have led to rapid and complete recovery.

After exposure to CsA, PBL in culture medium do not behave as they would in vivo. While addition of $R B C$ in vitro mimics a hydrophobic environment available for CsA equilibration in vivo, RBC underrepresent critical preferred CsA binding sites (e.g., CyP) that are present in vivo. Equilibration amongst these preferred sites may be the major determinant of overall CsA movement in vivo. Understanding the mechanisms involved in CsA movement, and the nature of its intracellular interactions, may offer a means of more specifically targeting this important but complex drug.

\section{Acknowledgments}

We wish to thank Dr. Linda Pilarski for providing cell lines and Dr. W. T. Beck (Memphis, TN) for permission to use them; Dr. Max Schreier (Sandoz AG, Basel, Switzerland) for providing anti-CsA Ab; Dr. Gerry Murphy (Sandoz, Dorval, Canada) for providing CsA; and Ms. P. Publicover for preparing the manuscript.

This work was supported by grants from the Alberta Heritage Foundation for Medical Research; the Kidney Foundation of Canada; the Medical Research Council of Canada; the Muttart Foundation; the Royal Canadian Legion; and Sandoz Canada.

\section{References}

1. Hsu, V. L., and I. M. Armitage. 1992. Solution structure of cyclosporin $A$ and a nonimmunosuppressive analog bound to fully deuterated cyclophilin. Biochemistry. 31:12778-12784.

2. Gaston, P., J. Kallen, T. Schirmer, J. N. Jansonius, M. G. M. Zurini, and M. D. Walkinshaw. 1993. X ray structure of a decameric cyclophilin-cyclosporin crystal complex. Nature (Lond.). 361:91-94.

3. Thériault, Y., T. M. Logan, R. Meadows, L. Yu, E. T. Olejniczak, T. F. Holzman, R. L. Simmer, and S. W. Fesik. 1993. Solution structure of the cyclosporine A/cyclophilin complex by NMR. Nature (Lond.) 361:88-91.

4. Clipstone, N. A., and G. R. Crabtree. 1992. Identification of calcineurin as a key signalling enzyme in T-lymphocyte activation. Nature (Lond.). 357:695697.

5. Foor, F., S. A. Parent, N. Morin, A. M. Dahl, N. Ramadan, G. Chrebet, K. A. Bostian, and J. B. Nielsen. 1992. Calcineurin mediates inhibition by FK506 and cyclosporine of recovery from $\alpha$-factor arrest in yeast. Nature (Lond.) 360:682-684

6. Schreiber, S. L., and G. R. Crabtree. 1992. The mechanism of action of cyclosporin A and FK506. Immunol. Today 13:136-142.

7. Batiuk, T. D., F. Pazderka, and P. F. Halloran. 1995. Calcineurin activity 
is only partially inhibited in leukocytes of cyclosporine-treated patients. Transplantation (Baltimore). 59:1400-1404.

8. Jain, J., P. G. McCaffrey, Z. Miner, T. K. Kerppola, J. N. Lambert, G. L. Verdine, T. Curran, and A. Rao. 1993. The T-cell transcription factor NFAT a substrate for calcineurin and interacts with Fos and Jun. Nature (Lond.). 365:352-355.

9. McCaffrey, P. G., B. A. Perrino, T. R. Soderling, and A. Rao. 1993. NF$\mathrm{AT}_{\mathrm{p}}$, a $\mathrm{T}$ lymphocyte DNA-binding protein that is a target for calcineurin and immunosuppressive drugs. J. Biol. Chem. 268:3747-3752.

10. McCaffrey, P. G., C. Luo, T. K. Kerppola, J. Jain, T. M. Badalian, A. M Ho, E. Burgeon, W. S. Lane, J. N. Lambert, T. Curran, et al. 1993. Isolation of the cyclosporin-sensitive T cell transcription factor NFATp. Science (Wash. DC). 262:750-754.

11. Frantz, B., E. C. Nordby, G. Bren, N. Steffan, C. V. Paya, R. L. Kincaid, M. J. Tocci, S. J. O'Keefe, and E. A. O'Neill. 1994. Calcineurin acts in synergy with PMA to inactivate $\mathrm{I} \kappa \mathrm{B} / \mathrm{MAD} 3$, an inhibitor of NF- $\kappa \mathrm{B}$. EMBO (Eur. Mol. Biol. Org.) J. 13:861-870.

12. Elliot, J. F., Y. Lin, S. B. Mizel, R. C. Bleackley, D. G. Harnish, and V. Paetkau. 1984. Induction of interleukin 2 messenger RNA inhibited by cyclosporine A. Science (Wash. DC). 226:1439-1441.

13. Granelli-Piperno, A., L. Andrus, and R. M. Steinman. 1986. Lymphokine and nonlymphokine mRNA levels in stimulated human cells: kinetics, mitogen requirements, and effects of cyclosporin A. J. Exp. Med. 163:992-937.

14. Reem, G. H., L. A. Cook, and J. Vilcek. 1983. Gamma interferon synthesis by human thymocytes and T lymphocytes inhibited by cyclosporin A. Science (Wash. DC). 221:63-65.

15. Kronke, M., W. J. Leonard, J. M. Depper, S. K. Arya, F. Wong-Staal, R. C. Gallo, T. A. Waldman, and W. C. Green. 1984. Cyclosporine A inhibits T cel growth factor gene expression at the level of mRNA transcription. Proc. Natl. Acad. Sci. USA. 81:5214-5218.

16. Granelli-Piperno, A. 1990. Lymphokine gene expression in vivo is inhibited by cyclosporine A. J. Exp. Med. 171:533-544.

17. Yatscoff, R. W., K. R. Copeland, C. J. Faraci, and T. D. Abbott. 1990 Monoclonal antibody assay evaluated for measuring cyclosporine in whole blood. Clin. Chem. 36:1969-1973.

18. Beck, W. T., T. J. Mueller, and L. R. Tanzer. 1979. Altered surface membrane glycoproteins in Vinca alkaloid-resistant human leukemic lymphoblasts. Cancer Res. 39:2070-2076.

19. Fruman, D. A., C. B. Klee, B. E. Bierer, and S. J. Burakoff. 1992.
Calcineurin phosphatase activity in T lymphocytes is inhibited by FK506 and cyclosporin A. Proc. Natl. Acad. Sci. USA. 89:3686-3690.

20. Pai, S. Y., D. A. Fruman, T. Leong, D. Neuberg, T. G. Rosano, C. McGarigle, J. H. Antin, and B. E. Bierer. 1994. Inhibition of calcineurin phosphatase activity in adult bone marrow transplant patients treated with cyclosporine A. Blood. 84:3974-3979.

21. Goldberg, H., V. Ling, P. Y. Wong, and K. Skorecki. 1988. Reduced cyclosporin accumulation in multidrug-resistant cells. Biochem. Biophys. Res. Commun. 152:552-558.

22. Dalgarno, D. C., M. W. Harding, A. Lazarides, R. E. Handschumacher and I. M. Armitage. 1986. HNMR studies on bovine cyclophilin: preliminary structural characterization of this specific cyclosporin A binding protein. Biochemistry. 25:6778.

23. Alberg, D. G., and S. L. Schreiber. 1993. Structure-based design of a cyclophilin-calcineurin bridging ligand. Science (Wash. DC). 262:248-250.

24. Ryffel, B., G. Woerly, V. F. J. Quesniaux, H. Hust, and B. M. J. Foxwell. 1992. Covalent binding of cyclosporine inhibits irreversibly T-lymphocyte activation. Biochem. Pharmacol. 43:953-960.

25. Kasiske, B. L., K. Heim-Duthoy, and J. Z. Ma. 1993. Elective cyclosporine withdrawal after renal transplantation. A meta-analysis. Review. JAMA (J. Am. Med. Assoc.). 269:395-400.

26. Sanders, C. E., J. J. Curtis, B. A. Julian, R. S. Gaston, P. A. Jones, D. A Laskow, M. H. Deierhoi, W. H. Barber, D. Phil, and A. G. Diethelm. 1993. Tapering or discontinuing cyclosporine for financial reasons: a single-center experience. Am. J. Kidney Dis. 21:9-15.

27. Coley, H. M., P. Workman, and P. R. Twentyman. 1991. Retention of activity by selected anthracyclines in a multidrug resistant human large cell lung carcinoma line without P-glycoprotein hyperexpression. Br. J. Cancer. 63:351357.

28. Versantvoort, C. H. M., H. J. Broxterman, H. M. Pinedo, E. G. E. de Vries, N. Feller, C. M. Kuiper, and J. Lankelma. 1992. Energy-dependent processes involved in reduced drug accumulation in multidrug-resistant human lung cancer cell lines without P-glycoprotein expression. Cancer Res. 52:17-23.

29. Damiani, D., M. Michieli, A. Michelutti, A. Geromin, D. Raspadori, R. Fanin, C. Savignano, M. Giacca, S. Pileri, and F. Mallardi. 1993. Expression of multidrug resistance gene (MDR-1) in human normal leukocytes. Haematologica. 78:12-17.

30. Chaudhary, P. M., E. B. Mechetner, and I. B. Roninson. 1992. Expression and activity of the multidrug resistance P-glycoprotein in human peripheral blood lymphocytes. Blood. 80:2735-2739. 